\title{
Conversion of myoblasts to physiologically active neuronal phenotype
}

\author{
Yumi Watanabe, ${ }^{1,7,8}$ Sei Kameoka, ${ }^{1,7,9}$ Vidya Gopalakrishnan, ${ }^{1}$ Kenneth D. Aldape, ${ }^{2}$ \\ Zhizhong Z. Pan, ${ }^{3}$ Frederick F. Lang, ${ }^{4}$ and Sadhan Majumder ${ }^{1,5,6,10}$ \\ ${ }^{1}$ Departments of Molecular Genetics, ${ }^{2}$ Pathology, ${ }^{3}$ Symptom Research and Biochemistry and Molecular Biology, \\ ${ }^{4}$ Neurosurgery, and ${ }^{5}$ Brain Tumor Center, The University of Texas M.D. Anderson Cancer Center, Houston, Texas 77030 , \\ USA; $^{6}$ The Program in Genes and Development, The University of Texas Graduate School of Biomedical Sciences at \\ Houston, Houston, Texas 77030, USA
}

Repressor element 1 (RE1)-silencing transcription factor (REST)/neuron-restrictive silencer factor (NRSF) can repress several terminal neuronal differentiation genes by binding to a specific DNA sequence (RE1) neuron-restrictive silencer element [NRSE]) present in their regulatory regions. REST-VP16 binds to the same RE1/NRSE, but activates these REST/NRSF target genes. However, it is unclear whether REST-VP16 expression is sufficient to cause formation of functional neurons either from neural stem cells or from heterologous stem cells. Here we show that the expression of REST-VP16 in myoblasts grown under muscle differentiation conditions blocked entry into the muscle differentiation pathway, countered endogenous REST/NRSF-dependent repression, activated the REST/NRSF target genes, and, surprisingly, activated other neuronal differentiation genes and converted the myoblasts to a physiologically active neuronal phenotype. Furthermore, in vitro differentiated neurons produced by REST-VP16-expressing myoblasts, when injected into mouse brain, survived, incorporated into the normal brain, and did not form tumors. This is the first instance in which myoblasts were converted to a neuronal phenotype. Our results suggest that direct activation of REST/NRSF target genes with a single transgene, REST-VP16, is sufficient to activate other terminal neuronal differentiation genes and to override the muscle differentiation pathways, and they suggest that this approach provides an efficient way of triggering neuronal differentiation in myoblasts and possibly other stem cells.

[Keywords: REST/NRSF; REST-VP16; myoblasts; neuronal differentiation; muscle differentiation; stem cells]

Supplemental material is available at http://www.genesdev.org.

Received December 17, 2003; revised version accepted March 16, 2004.

Neuroregeneration is being studied intensely as a way to repair and restore damaged or diseased neurons. One approach is to manipulate various factors that control the ability of neural stem cells (NSCs) in the adult brain to regenerate neurons (Keyoung et al. 2001; Horner and Gage 2002; Ourednik et al. 2002; Panchision and McKay 2002; Park et al. 2002a,b; Galli et al. 2003; Goldman 2003; Nunes et al. 2003). Another approach is to convert nonneural stem cells or progenitor cells to the neuronal phenotype through transdifferentiation. Embryonic stem cells (ESCs) and bone marrow stem cells have been used

\footnotetext{
${ }^{7}$ These authors contributed equally to this study.

Present addresses: ${ }^{8}$ Dept. of Anatomy and Neurobiology, Graduate School of Medicine and Faculty of Medicine, Kyoto Univ., Kyoto 6068501 Japan; ${ }^{9}$ Dept. of Molecular and Cellular Biology, Harvard Univ., Cambridge, MA 02138, USA.

${ }^{10}$ Corresponding author.

E-MAIL majumder@mdanderson.org; FAX (713) 792-6054.

Article published online ahead of print. Article and publication date are at http://www.genesdev.org/cgi/doi/10.1101/gad.1179004.
}

for this purpose (Snyder and Vescovi 2000; Frisen 2002; Sanchez-Ramos 2002; Tsai et al. 2002; Brivanlou et al. 2003). Conversion of heterologous stem cells other than ESCs to neurons would have a tremendous impact, given the political and ethical concerns attending therapeutic use of human ESCs (Wurmser and Gage 2002). However, in some cases, formation of neurons from bone marrow stem cells may be due to fusion of contaminating ESCs rather than actual transdifferentiation (Wurmser and Gage 2002), highlighting the importance of using a homogenous stem cell population for transdifferentiation experiments.

C2C12 myoblasts are an excellent, well characterized mouse model for muscle differentiation (Walsh and Perlman 1997). When cultured with high concentrations of growth factors, these homogeneous cells proliferate as mononucleated progenitor cells. In contrast, when cultured with low concentrations of growth factors, they enter the differentiation pathway, express muscle differentiation proteins, and fuse to form terminally differen- 
tiated, multinucleated myotubes. The molecular mechanisms responsible for this differentiation process have been studied extensively. Although less examined, under certain conditions $\mathrm{C} 2 \mathrm{C} 12$ myoblasts can also differentiate into adipocyte-like cells (Teboul et al. 1995) or into an osteoblast lineage (Katagiri et al. 1994). The spectacular dedifferentiation of terminally differentiated C2C12 myotubes into proliferating mononucleated cells and their subsequent redifferentiation into cells expressing myogenic, chondrogenic, adipogenic, and osteogenic markers (Odelberg et al. 2000; McGann et al. 2001) make C2C12 myoblasts an excellent yet simple system for studying principles of stem cell plasticity. Although these cells can differentiate and dedifferentiate into various cell types, $\mathrm{C} 2 \mathrm{C} 12$ myoblasts or dedifferentiated myotubes do not give rise to neuronal cells, suggesting that certain necessary factors are absent, negative factors are present, or both.

The differentiation of NSCs into neurons is generally believed to involve four steps characterized by the expression and action of specific gene products (Immaneni et al. 2000; Lawinger et al. 2000). In the first step, NSCs, which can multiply and make their own kind under one set of conditions and differentiate under other conditions, express p75 and nestin. The next step, the neuronal determination step, is characterized by the action of the basic helix-loop-helix proteins, such as MASH, $\mathrm{MATH}$, and neuroD3/neurogenin. This is followed by the commitment step, in which gene products such as neuroD1/2, Myt1, and neurofilament 150 are expressed. The terminal differentiation step is characterized by the expression of gene products such as SCG10, sodium channel type II, synapsin, glutamate receptor, and acetylcholine receptor. It is mostly the terminal differentiation genes that are direct targets of the repressor element 1 (RE1)-silencing transcription factor (REST)/neuron-restrictive silencer factor (NRSF; Chong et al. 1995; Schoenherr and Anderson 1995). REST/NRSF contains a DNA-binding domain and two repressor domains and is expressed mostly in nonneuronal cells. It blocks transcription of its target genes by binding to a specific consensus RE1-binding site/neuron-restrictive silencer element $(R E 1 / N R S E)$ present in the genes' regulatory regions. REST/NRSF is down-regulated during the induction and maintenance of the neuronal phenotype (Ballas et al. 2001), and overexpression of REST/NRSF in differentiating neurons disrupts neuronal gene expression and causes axon guidance errors (Paquette et al. 2000).

Neuronal differentiation is regulated, particularly at the beginning stages, by some negative regulators (Ross et al. 2003). This raises the possibility that if we can bypass these steps and directly activate terminal differentiation genes, NSCs that are otherwise restricted at the preceding steps can then differentiate into neurons. Furthermore, such a manipulation could also convert nonneural progenitor cells to a neuronal phenotype. To examine this possibility, we previously constructed a recombinant transcription factor, REST-VP16, by replacing the repressor domains of REST/NRSF with the acti- vation domain of the herpes simplex virus protein VP16. Because REST-VP16 still contains the DNA-binding domain of REST/NRSF, we found that REST-VP16, when transiently expressed in mammalian cells, operates through the RE1/NRSE, competes with endogenous REST/NRSF for DNA binding, and activates REST/ NRSF target genes (Immaneni et al. 2000; Lawinger et al. 2000).

Although NSCs have been converted into muscles (Galli et al. 2000, 2003), muscle progenitor cells have shown tremendous potential in the treatment of muscle and connective-tissue disorders (Deasy et al. 2001; Peng and Huard 2003), and muscle-derived stem cells have been converted into hematopoietic cells (Jankowski et al. 2002; Cao et al. 2003), muscle progenitor cells have not been converted into neurons. Here, we asked whether direct activation of REST/NRSF target genes via REST-VP16 can convert C2C12 myoblasts to the neuronal phenotype.

\section{Results}

REST-VP16 counters endogenous REST/NRSF activity in myoblasts

To determine whether $\mathrm{C} 2 \mathrm{C} 12$ cells express endogenous REST/NRSF activity and, if present, to quantify this activity, we used two reporter plasmid DNAs that we used previously (Immaneni et al. 2000; Lawinger et al. 2000). The first is $\mathrm{pNaCh}$ (also called pSDK7), which contains the bacterial chloramphenicol acetyl transferase (CAT) reporter gene under the control of sodium channel type II promoter/enhancer ( $\mathrm{NaCh}$ ) elements (Chong et al. 1995). The $\mathrm{NaCh}$ elements are mammalian native neuronal promoter/enhancer sequences that contain the REST/ NRSF-binding site (+RE) and are acted on by functional REST/NRSF (Chong et al. 1995). The second reporter plasmid, pNaCh $\Delta$ RE1 (also called pMB4), contains the CAT reporter gene under the control of the "minimal" $\mathrm{NaCh}$ elements without the RE1 sequence (-RE). Functional REST/NRSF does not repress the promoter activity from this plasmid (Chong et al. 1995). Thus, when functional REST/NRSF is present in the cell, the CAT activity from $\mathrm{pNaCh}(+\mathrm{RE})$ would be lower than that from $\mathrm{pNaCh}(-\mathrm{RE})$. In this experiment, we also used PC12 cells, which do not express endogenous REST/ NRSF, and HeLa cells, which express endogenous REST/ NRSF /Chong et al. 1995; Schoenherr and Anderson 1995; Immaneni et al. 2000; Lawinger et al. 2000). These cells were transiently cotransfected with the reporter plasmids $\mathrm{pNaCh}(+\mathrm{RE})$ or $\mathrm{pNaCh}(-\mathrm{RE})$ and an internal control plasmid, pCMV- $\beta g a l$, which contains the $\beta$-galactosidase reporter gene under the control of cytomegalovirus promoter. The average CAT values, normalized to $\beta$-galactosidase activity, from three experiments were denoted as a percentage of $\mathrm{pNaCh}(-\mathrm{RE})$ promoter activity. As shown in Figure 1A, whereas PC12 cells did not show REST/NRSF activity, HeLa cells did, as expected. Under these conditions, C2C12 cells showed high endogenous REST/NRSF activity.

To determine whether transient expression of REST- 
A

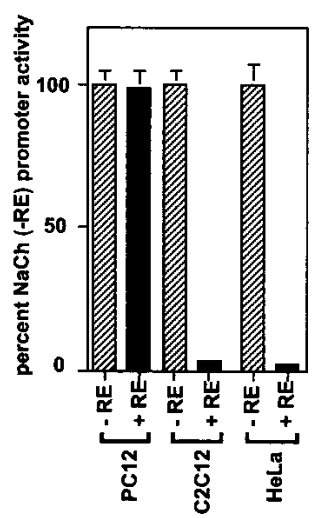

B

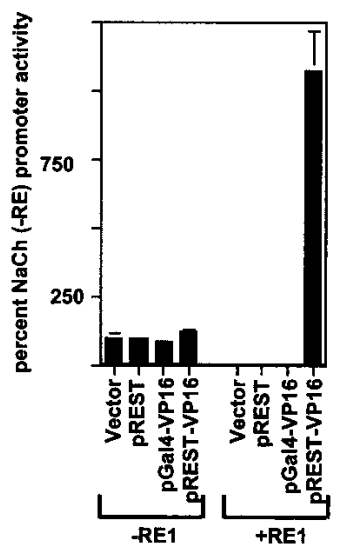

Figure 1. Myoblasts express REST/NRSF activity, which can be countered by REST-VP16. (A) C2C12 cells express endogenous REST/NRSF activity. Endogenous REST/NRSF activity was determined in $\mathrm{C} 2 \mathrm{C} 12$ cells, PC12 cells (negative control), and HeLa cells (positive control) by transfection of a reporter plasmid containing the CAT reporter gene under the control of endogenous $\mathrm{NaCh}$ promoter with $(+\mathrm{RE})$ or without $(-\mathrm{RE})$ the REST/NRSF-binding site. In these experiments, cotransfection of an internal control plasmid, pCMV- $\beta$-gal, was used. The average CAT values, normalized to $\beta$-galactosidase activity, from triplicate experiments are shown as a percent of $\mathrm{NaCh}(-\mathrm{RE})$ promoter activity. (B) The endogenous REST/NRSF activity in $\mathrm{C} 2 \mathrm{C} 12$ cells can be countered by REST-VP16. Expression vector (Vector) and expression vector encoding REST/NRSF (pREST), Gal4-VP16 (pGal4-VP16), and REST-VP16 (pREST-VP16) were cotransfected with $\mathrm{NaCh}(+\mathrm{RE})$ or $\mathrm{NaCh}(-\mathrm{RE})$ reporter plasmids in $\mathrm{C} 2 \mathrm{C} 12$ cells and the promoter activity was determined as in $A$. The value for $\mathrm{NaCh}(-\mathrm{RE})$ in the presence of vector DNA was denoted as $100 \%$.

VP16 in C2C12 cells could counter endogenous REST/ NRSF-dependent repression and cause stimulation of the RE-dependent promoter activity, we carried out the transcriptional assays using $\mathrm{pNaCh}(+\mathrm{RE})$ and $\mathrm{pNaCh}(-\mathrm{RE})$ in these cells as described above. Vector DNA and plasmid DNA encoding REST or Gal4-VP16 were used as control DNA. As shown in Figure 1B, none of the plasmids affected the $\mathrm{NaCh}(-\mathrm{RE})$ promoter activity. In contrast, the $\mathrm{NaCh}(+\mathrm{RE})$ promoter activity, compared with $\mathrm{NaCh}(-\mathrm{RE})$, was repressed in the presence of the vector, pREST, and pGal4-VP16 plasmids, indicating endogenous REST/NRSF activity. On the other hand, pRESTVP16 could stimulate $\mathrm{NaCh}(+\mathrm{RE})$ promoter activity, indicating that REST-VP16 can functionally counter the endogenous REST/NRSF-dependent repression and stimulate the RE-dependent promoters in $\mathrm{C} 2 \mathrm{C} 12$ cells, as was seen in other cell types (Immaneni et al. 2000; Lawinger et al. 2000).

\section{Stable REST-VP16 expression in proliferating myoblasts causes activation of neuronal differentiation genes}

To investigate the role of long-term expression of RESTVP16 in myoblasts, we generated C2C12 clonal cells by

using the bidirectional doxycycline-regulated vector pBig2r (Strathdee et al. 1999). The clonal cell line C2C12-RV stably expressed the REST-VP16 protein when grown without doxycycline (-Dox) for $2 \mathrm{~d}$, as shown by Western blotting (Fig. 2A). In contrast, C2C12 (-Dox) cells and C2C12-RV cells grown with doxycycline (+Dox) did not produce detectable levels of RESTVP16 protein.

To determine whether the REST-VP16 protein was transcriptionally active in the clonal cells, we used a reporter plasmid system that we devised previously (Immaneni et al. 2000; Lawinger et al. 2000). We transfected plasmids containing a luciferase reporter gene under the control of a TATA box alone (pT.luc) or a TATA box plus two copies of the wild-type RE1/NRSE sequence (pRE.T.luc) into C2C12 and C2C12-RV (+ and -Dox) cells. These experiments showed that C2C12-RV (-Dox) cells activated the REST-dependent basal promoter 145fold more strongly than C2C12 cells (+ or -Dox) did and 20-fold more strongly than C2C12-RV (+Dox) cells (Fig. 2B). Thus, C2C12-RV (-Dox) cells produced high levels of transcriptionally functional REST-VP16 protein.

To determine whether the REST-VP16 protein produced in the clonal cells activated its cellular target, the terminal neuronal differentiation genes, we assayed the Western blot in Figure 2A with an anti-synapsin antibody. As shown in Figure 2A, strong synapsin expression
A

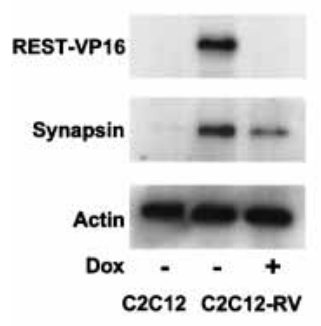

B

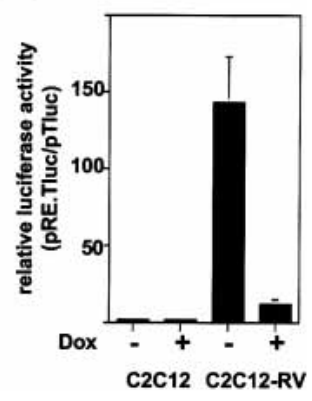

Figure 2. Stable REST-VP16 expression in proliferating myoblasts causes activation of neuronal differentiation genes. $(A)$ C2C12-REST-VP16 clonal cells (C2C12-RV) produced the REST-VP16 protein in the absence of doxycycline (-Dox) as assayed by Western blotting using anti-VP16 antibodies. Such REST-VP16 production was not observed in the parental C2C12 cells or C2C12-RV cells in the presence of doxycycline (+Dox). When the same blot was probed with anti-synapsin antibody, expression of synapsin was observed in C2C12-RV(-Dox) cells but not in $\mathrm{C} 2 \mathrm{C} 12$ cells. A low level of synapsin signal was also observed in C2C12-RV (+Dox) clones, presumably as a result of the leakiness of the doxycycline-regulated system. Expression of actin was measured as an internal control by using anti-actin antibodies. (B) The C2C12-RV (-Dox) cells producing the RESTVP16 protein can activate the basal TATA-box promoter through the RE1-binding sites. The cells were transfected with the reporter plasmid pTluc or pRE.Tluc along with an internal control plasmid, PCMV- $\beta$-gal, and analyzed as described in the Materials and Methods section. REST-VP16-dependent stimulation was calculated as pRE.Tluc expression/pTluc expression, and is shown as relative luciferase activity. 
was detected only in REST-VP16-expressing cells, indicating that REST-VP16 activated its cellular target genes in C2C12-RV (-Dox) cells. Interestingly, a low level of synapsin expression was also detected in C2C12-RV (+Dox) cells, probably as a result of the leakiness of the doxycycline-regulated system.

REST-VP16 expression in myoblasts growing under muscle differentiation conditions blocks muscle differentiation and produces neuronal phenotype

To determine the effect of the expression of REST-VP16 in C2C12 cells grown under muscle-differentiation conditions, we grew C2C12 and C2C12-RV cells with low concentrations of growth factors $\mathrm{C} 2 \mathrm{C} 12(\mathrm{D})$ and $\mathrm{C} 2 \mathrm{C} 12$ $\mathrm{RV}(\mathrm{D})$ (+ and -Dox) for $6 \mathrm{~d}$. A light-microscopic examination revealed that in the absence of REST-VP16 expression in $\mathrm{C} 2 \mathrm{C} 12$ (D) or C2C12-RV(D) (+Dox) cells, the cells formed multinucleated muscle fibers (Fig. 3A), as expected. In contrast, cells expressing REST-VP16 (C2C12-RV [-Dox] cells) did not form muscles. Instead, they formed mononucleated cells, some of which had long, neurite-like structures. To further characterize these cells, we performed a Western blot analysis for muscle and neuronal proteins. As shown in Figure 3B, REST-VP16 was not detected in C2C12(D) cells and C2C12-RV(D) (+Dox) cells, and the myosin heavy chain $(M H C)$ gene, a marker for differentiated muscles, was detected. Expression of synapsin, a target of REST-VP16, was not detected in C2C12(D) cells. A low level of synapsin expression was detected in C2C12-RV(D) (+Dox) cells, presumably because of the leakiness of the doxycycline system, similar to that seen earlier (Fig. 2A). In contrast, C2C12-RV(D) (-Dox) cells produced the RESTVP16 protein and a high level of synapsin but did not express MHC. Interestingly, C2C12-RV(D) (-Dox) cells also produced MAP2, indicating that expression of
REST-regulated neuronal differentiation genes through REST-VP16 also triggers the activation of other neuronal differentiation genes that are not direct targets of REST/ NRSF. This correlation between REST-VP16 and MAP2 expressions was observed in almost all cells.

To confirm the inverse correlation between RESTVP16 expression and MHC expression, C2C12(D), C2C12-RV(D) (+Dox), and C2C12-RV(D) (-Dox) cells were subjected to double immunofluorescence imaging with anti-VP16 and anti-MHC antibodies. Expression of MHC, but not REST-VP16, was observed in C2C12(D) cells (Fig. 3C). In contrast, C2C12-RV(D) (-Dox) cells did not express MHC but did express REST-VP16. The leaky growth conditions allowed some C2C12-RV(D) (+Dox) cells to express REST-VP16 and some to express MHC. However, the cells that expressed REST-VP16 did not express MHC, and the cells that expressed MHC did not express REST-VP16. Thus, these experiments showed that expression of REST-VP16 in C2C12 cells under muscle differentiation conditions blocked muscle formation and MHC gene expression and caused the expression of neuronal terminal differentiation marker genes, some of which are targets of REST/NRSF and others not.

The differentiation of $\mathrm{C} 2 \mathrm{C} 12$ cells into muscle follows a very well-defined pathway, expressing several muscle differentiation factors in a sequential fashion (Walsh and Perlman 1997; Odelberg et al. 2000; McGann et al. 2001; Shen et al. 2003). Myogenin is one such factor that appears at the onset of muscle differentiation in C2C12 cells at $\sim 2 \mathrm{~d}$ in muscle differentiation medium (Shen et al. 2003). To examine whether REST-VP16-mediated entry of C2C12-RV cells to the neuronal pathway occurred before they entered the muscle differentiation pathway, or whether C2C12-RV cells had to wait until they entered the muscle differentiation pathway, we assayed the Western blot in Figure 3D with an anti-myogenin antibody. The level of actin expression was used as an inter-

Figure 3. Stable expression of functional REST-VP16 in myoblasts growing under muscle differentiation conditions blocks entry into the muscle differentiation pathway, subsequent muscle formation, and the $M H C$ gene expression, and causes the expression of neuronal differentiation genes and formation of neuritelike structures, but does not cause expression of glial differentiation genes. $(A-C) \mathrm{C} 2 \mathrm{C} 12$, C2C12-RV (+Dox), and C2C12-RV (-Dox) cells were cultured in DMEM with $2 \%$ horse serum for $6 \mathrm{~d}[\mathrm{C} 2 \mathrm{C} 12(\mathrm{D}), \mathrm{C} 2 \mathrm{C} 12-\mathrm{RV}(\mathrm{D})$ (+Dox), and C2C12-RV(D) (-Dox), respectively] and examined by light microscopy $(A)$, Western blot analysis $(B)$, and fluorescent microscopy $(C)$. Anti-MAP2, anti-myosin heavy chain, and anti-synapsin antibodies were used. $(D)$ Cell extracts prepared from $\mathrm{C} 2 \mathrm{C} 12$ and $\mathrm{C} 2 \mathrm{C} 12-\mathrm{RV}$ (-Dox) cells at various days in differentiation medium (day) were assayed by Western blotting with anti-GFAP and anti-myogenin antibodies. Anti-actin was used as an internal control. Mouse brain extract was used as a positive control for GFAP expression.

A

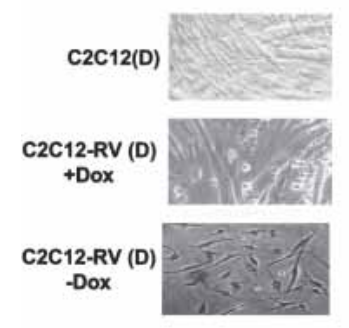

B
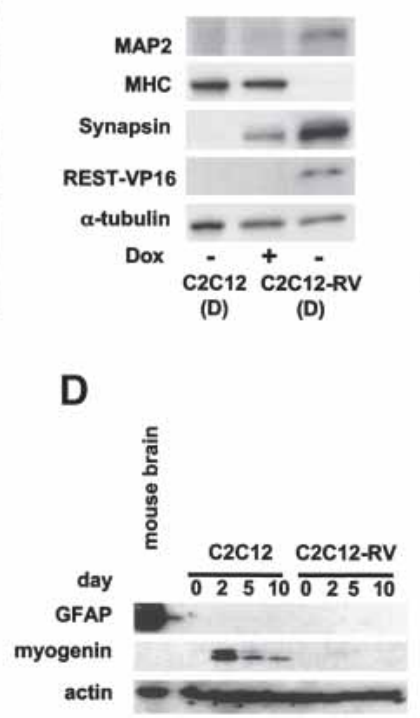

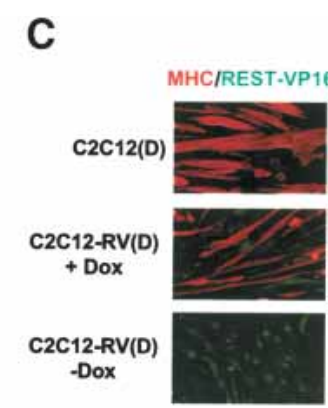


nal control, as before. As shown in Figure 3D, the onset of myogenin expression appeared in $\mathrm{C} 2 \mathrm{C} 12$ cells at approximately day 2 of muscle differentiation and then decreased with further differentiation, as expected (Shen et al. 2003). In contrast, C2C12-RV cells did not show myogenin expression during any time of their differentiation, indicating that REST-VP16 expression in C2C12-RV cells growing under muscle differentiation conditions immediately turned them towards the neuronal pathway without entering the muscle differentiation pathway.

To confirm that C2C12-RV(D) cells did not express glial markers, such as glial fibrillary acidic protein (GFAP), cell extracts prepared from C2C12 and C2C12$\mathrm{RV}$ cells at various days in differentiation medium were subjected to Western blotting analysis with anti-GFAP antibody. Mouse brain extract was used as a positive control for the expression of GFAP, and anti-actin antibody was used as an internal control. As shown in Figure 3D, GFAP was not expressed in any of these cells, indicating that REST-VP16 expression in C2C12 cells converted them only into neuronal phenotype.

Stable REST-VP16 expression in myoblasts enables them to survive mitotic inhibitors and exhibit neuronal phenotype

To examine whether C2C12-RV(D) (-Dox) cells that are grown under muscle differentiation conditions can survive in the presence of mitotic inhibitors, a property of nondividing neurons, C2C12-RV(D) (-Dox) cells were further cultured for $14 \mathrm{~d}$ in the presence of mitotic inhibitors. The cells were then examined by light and immunofluorescence microscopy with anti-MAP2 and anti-neurofilament antibodies. As shown in Figure 4A, most of the C2C12-RV(D) (-Dox) cells, unlike the C2C12 cells, survived the mitotic inhibitors, and expressed the MAP2 and neurofilament proteins.
To determine the changes in the global gene expression patterns of the various cell types, we performed gene expression profiling of $\mathrm{C} 2 \mathrm{C} 12, \mathrm{C} 2 \mathrm{C} 12(\mathrm{D})$, and C2C12-RV(D) (-Dox) cells using Affymetrix mouse chips. A large number of genes were differentially expressed among the three cell types. The genes most differentially expressed in the C2C12-RV(D) (neuron) cells compared with the C2C12(D) (muscle) cells are shown in the Supplemental Material (Supplementary Table 1S). Likewise, the genes most differentially expressed in C2C12(D) cells in comparison to C2C12-RV(D) cells are shown in Supplementary Table 2S. The C2C12(D) cells expressed mostly muscle differentiation genes, as expected, and the C2C12-RV(D) cells expressed a large number of neuronal differentiation genes (Schoenherr et al. 1996; Lunyak et al. 2002). These genes included widely used neuronal markers, such as MAP2 and neuronal $\beta$-tubulin, but also neuronal receptors such as glycine receptor, glutamate receptor, adrenergic receptor, cholinergic receptor, etc. They also included neuronal channels, such as voltage-gated calcium channel, calcium-activated chloride channel, voltage-gated potassium channel, voltage-gated sodium channel, etc. Among the topmost up-regulated genes in the $\mathrm{C} 2 \mathrm{C} 12$ $\mathrm{RV}(\mathrm{D})$ cells were the genes that code for components of neuroendocrine secretory vesicles (Tooze et al. 2001), such as secretogranin II, chromogranin A, and brain-specific Purkinje cell protein 4 . We performed a Western blot analysis with an anti-secretogranin II antibody that confirmed that secretogranin II was expressed only in the C2C12-RV(D) (-Dox) cells, not in the C2C12 (-Dox), C2C12(D) (-Dox), or C2C12-RV(D) (+Dox) cells (Fig. 4B).

To further characterize the neuronal properties of C2C12-RV(D) (-Dox) cells, we performed an RT-PCR assay to determine the expression of several neuronal genes in $\mathrm{C} 2 \mathrm{C} 12(\mathrm{D})$ and $\mathrm{C} 2 \mathrm{C} 12-\mathrm{RV}(\mathrm{D})$ (-Dox) cells. As shown in Figure 4C, several well characterized neuronal REST-target genes such as neuronal $\beta$-tubulin, SCG10,
A

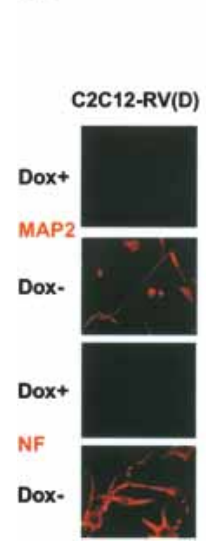

B

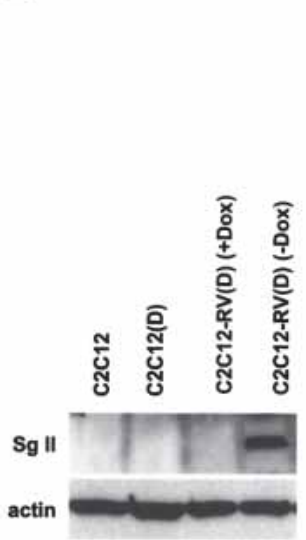

C

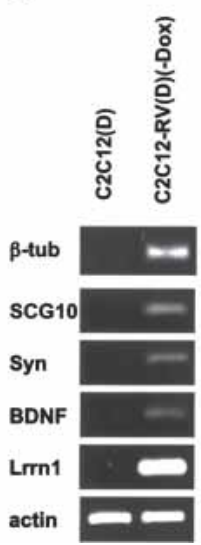

D

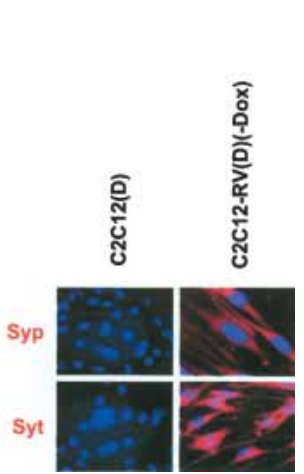

Figure 4. Stable REST-VP16 expression in myoblasts enables them to survive mitotic inhibitors and exhibit neuronal phenotype. (A) C2C12-RV cells were cultured with and without Dox in differentiation medium without mitotic inhibitors for $6 \mathrm{~d}$ and then with mitotic inhibitors for another $14 \mathrm{~d}$. These cells were then examined by immunofluorescence imaging with anti-MAP2 and anti-neurofilament (NF) antibodies. (B) Expression of secretogranin II in C2C12-RV(D) (-Dox) cells. Cell extracts from $\mathrm{C} 2 \mathrm{C} 12, \mathrm{C} 2 \mathrm{C} 12(\mathrm{D})$, $\mathrm{C} 2 \mathrm{C} 12-\mathrm{RV}(\mathrm{D})$ (+Dox), and C2C12-RV(D) (-Dox) cells were subjected to a Western blot analysis with anti-secretogranin II antibody. Anti-actin was used as an internal control. $(C)$ Expression of neuronal markers, such as neuronal $\beta$-tubulin, SCG10, synapsin (syn), BDNF, and Lrrn1 in C2C12-RV(D) (-Dox) cells but not in C2C12(D) (-Dox) cells as assayed by RT-PCR. Actin was used as an internal control. (D) Expression of synaptophysin and synaptotagmin in C2C12$\mathrm{RV}(\mathrm{D})$ (-Dox) cells. Immunofluorescence analysis was performed with C2C12(D) and C2C12-RV(D) (-Dox) cells using anti-synaptophysin (Syp) and anti-synaptotagmin (Syt) antibodies. Cell nuclei were stained with DAPI. 
synapsin, and BDNF were up-regulated in C2C12-RV(D) (-Dox) cells compared with C2C12(D) cells. Interestingly, C2C12-RV(D) (-Dox) cells but not C2C12(D) cells also expressed leucine-rich repeat protein 1, neuronal (Lrrn 1), a neuronal gene that is not known to be a direct target of REST/NRSF but was observed in the Affymetrix microarray data.

To further characterize the neuronal properties of $\mathrm{C} 2 \mathrm{C} 12-\mathrm{RV}(\mathrm{D})$ (-Dox) cells by immunofluorescence assay, we stained C2C12(D) and C2C12-RV(D) (-Dox) cells with anti-synaptophysin and anti-synaptotagmin antibodies. Synaptophysin is a known target of REST/NRSF (Schoenherr et al. 1996), and synaptotagmin was found to be up-regulated in C2C12-RV(D) cells in the Affymetrix microarray data (Supplementary Table 1S). As shown in Figure 4D, C2C12-RV(D) but not C2C12(D) cells expressed these neuronal markers both in the cell body and in neurites, as expected (Dandoy-Dron et al. 2003; Ogoshi and Weiss 2003). Thus, these experiments indicated that there was a global change in the gene expression profiles of these cell types and that REST-VP16-expressing myoblasts began expressing a large number of neuronal genes upon differentiation.

\section{REST-VP16 expression in myoblasts produces neurons with physiological activities}

Depolarization-dependent calcium influx is an intrinsic property of synaptic vesicles, occurs in both mature and developing neuronal processes, and is independent of the presence of synaptic contacts (Bischofberger and Schild 1995; Matteoli et al. 1995; Pincus et al. 1998; Roy et al. 2000; Shen et al. 2003). This influx also occurs in functional muscle fibers (Chawla et al. 2001). To determine whether C2C12-RV(D) (-Dox) cells also undergo depolarization-dependent calcium influx, we measured intracellular $\mathrm{Ca}^{++}$levels by loading live C2C12, C2C12(D), and C2C12-RV(D) cells with the fluorescent calcium indicator Fluo-3 in the absence of Dox and examined them with a confocal laser system. Fluo-3 is practically nonfluorescent unless bound to $\mathrm{Ca}^{++}$. These cells were then depolarized with high $\mathrm{K}^{+}$, and the fluorescence was mea- sured every $0.25 \mathrm{sec}$ for a total of $5 \mathrm{sec}$. As shown in Figure 5, there was a rapid, reversible calcium influx in response to $\mathrm{K}^{+}$in $\mathrm{C} 2 \mathrm{C} 12(\mathrm{D})$ and $\mathrm{C} 2 \mathrm{C} 12-\mathrm{RV}(\mathrm{D})$ cells but not C2C12 cells. Thus, both C2C12(D) and C2C12$\mathrm{RV}(\mathrm{D})$ cells showed physiological activity, namely, depolarization-dependent calcium influx. C2C12(D) and C2C12-RV(D) cells were cultured under similar conditions, which suggests that the neuronal properties of C2C12-RV(D) cells are not due to the differences in culture conditions but are inherent properties of these cells.

Because depolarization-dependent calcium influx is a property of both neurons and muscles, we wanted to examine other physiological properties that are specific to neurons. Synaptic vesicle recycling is a property of living nerve terminals, and the fluorescent dye FM1-43 is frequently used to label nerve terminals undergoing synaptic vesicle recycling (Betz and Bewick 1992). The dye, which is fluorescent upon excitation at $470 \mathrm{~nm}$, can be internalized from the culture medium during synaptic vesicle cycling with high $\mathrm{K}^{+}$. It does not transfer from internalized vesicles to an endosome-like compartment during the recycling process, and therefore it is possible to measure fluorescence (Murthy and Stevens 1998). Furthermore, each fluorescent spot is believed to be a cluster of hundreds of synaptic vesicles (Betz and Bewick 1992). This is an inherent property of neurons and is not observed in muscles. To determine whether C2C12(D) and C2C12-RV(D) cells, both of which underwent depolarization-dependent calcium influx, also experienced synaptic vesicle recycling, these cells were loaded with FM1-43 in high-KCl buffer and then washed to remove excess dye on the plasma membrane. The internalization of FM1-43 was then detected by excitation at $470 \mathrm{~nm}$, and the fluorescent spots were examined by fluorescence microscopy. Fluorescent spots were observed in the neurites of $\mathrm{C} 2 \mathrm{C} 12 \mathrm{RV}(\mathrm{D})$ cells but not in $\mathrm{C} 2 \mathrm{C} 12(\mathrm{D})$ cells or C2C12 myoblasts (Fig. 6A), indicating that C2C12$\mathrm{RV}(\mathrm{D})$ cells have the properties of functional neuron-specific synapses.

Glutamate-induced calcium influx is another intrinsic property of neurons. To determine whether C2C12$\mathrm{RV}(\mathrm{D})$ cells have this property, we measured the cells'
Figure 5. Stable expression of RESTVP16 in myoblasts growing under muscle differentiation conditions produced neurons with physiological properties. Differentiated C2C12 and C2C12$\mathrm{RV}$ cells show depolarization-dependent calcium influx. C2C12, C2C12(D) or C2C12-RV(D) (-Dox) cells were loaded with $25 \mu \mathrm{M}$ Fluo-3 AM for $60 \mathrm{~min}$ at room temperature. Fluo-3 AM solution was replaced with high-KCl Ringer solution, and an image was taken at every 0.25 sec for a total of $5 \mathrm{sec}$ after depolarization. The results of three independent experiments with C2C12-RV(D) (-Dox) cells are shown. Fluorescence intensity for experiment is shown in the bottom panel.
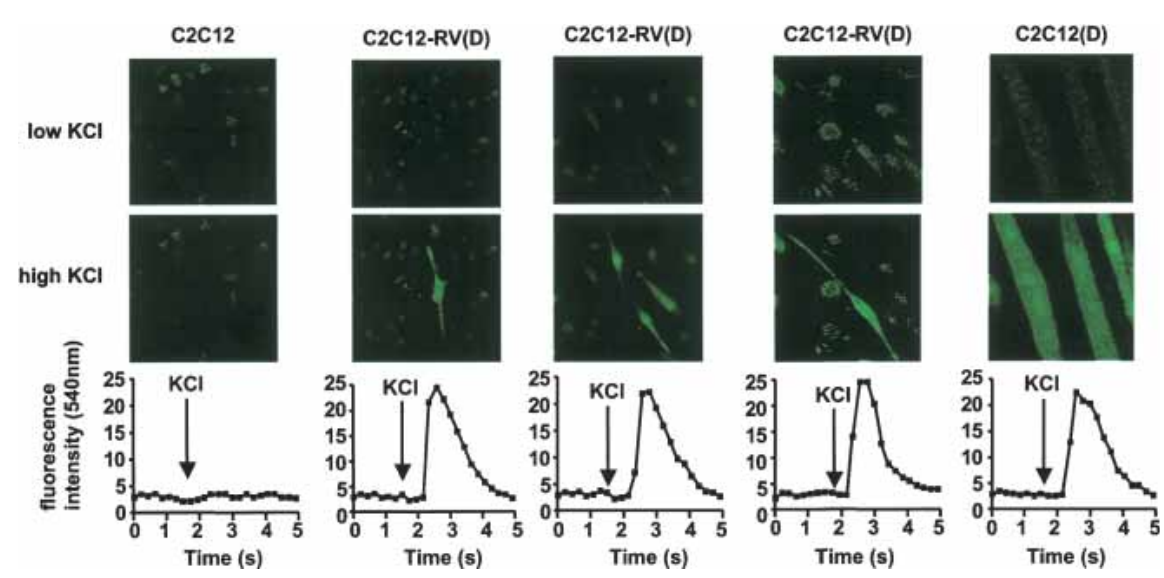

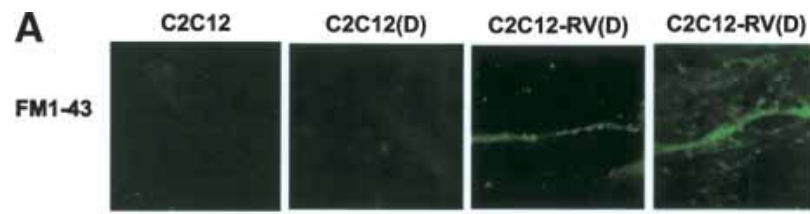

B

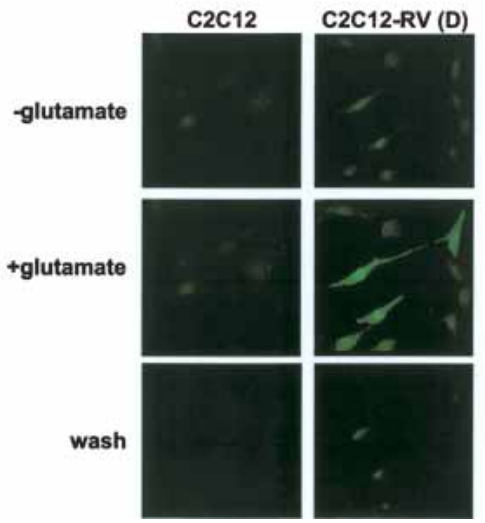

Figure 6. Stable expression of REST-VP16 in myoblasts growing under muscle differentiation conditions produced neurons with physiological properties. (A) Uptake of FM1-43 by C2C12$\mathrm{RV}(\mathrm{D})$ (-Dox) shows synaptic vesicle cycling with $\mathrm{KCl}$ depolarization. C2C12, C2C12(D) or C2C12-RV(D) (-Dox) cells were loaded with $15 \mu \mathrm{M}$ FM1-43 with high-KCl Ringer solution for 5 min at room temperature. Cells were washed with Ringer solution without a dye for 15 min to remove superficial FM1-43 on plasma membrane. The results of two independent experiments are shown. (B) Differentiated C2C12-RV cells show glutamate-induced calcium influx. C2C12 or C2C12-RV(D) (-Dox) cells were loaded with $25 \mu \mathrm{M}$ Fluo-3 AM for $60 \mathrm{~min}$ at room temperature, and the cells were treated as described in Figure 5, except that $10 \mu \mathrm{M}$ glutamate was added instead of $\mathrm{KCl}$. The fluorescent signal returned to baseline upon wash.

intracellular $\mathrm{Ca}^{++}$levels with and without glutamate, using the fluorescent calcium indicator Fluo-3 as described above. As shown in Figure 6B, C2C12-RV(D) cells but not $\mathrm{C} 2 \mathrm{C} 12$ cells underwent a rapid increase in intracellular $\mathrm{Ca}^{++}$in the presence of glutamate as evidenced by the fluorescent signal, which returned to baseline upon wash. Thus, taken together, the above experiments showed that C2C12-RV(D) cells exhibit physiological properties of neurons.

\section{In vitro differentiated neurons produced by REST-VP16-expressing myoblasts incorporate into adult brain without forming tumors}

Next, we wanted to examine whether in vitro differentiated neurons produced by REST-VP16-expressing myoblasts could survive in the brain and whether they formed tumors. We injected $\mathrm{C} 2 \mathrm{C} 12$ and in vitro differentiated C2C12-RV(D) cells into the cerebella of mice. We performed these experiments with already differentiated neurons to exclude the possibility of cell fusion in the brain as a mechanism of neuron formation. We sacrificed the mice $8 \mathrm{wk}$ later, and examined the status of the injected cells in paraffin sections of the brains by hematoxylin-eosin and immunohistochemical staining with anti-VP16 antibodies. As a control, we also used a neuronal tumor (meduloblastoma) cell line. However, the latter sets of mice were sacrificed after $4 \mathrm{wk}$, as they showed signs of morbidity by that time. Whereas the medulloblastoma tumor cell line formed a large tumor within $4 \mathrm{wk}$, neither C2C12 nor C2C12-RV(D) cells formed tumors after $8 \mathrm{wk}$ (Supplementary Fig. 1S). As shown in Figure 7, C2C12-RV(D) cells, which are tagged with VP16 protein, survived in the brain as detected by the presence of signal with anti-VP16 immunohistochemistry, and appeared to be distributed in the brain structures [the magnified view of C2C12-RV(D) cells shows nuclear localization of VP16 signal]. To determine whether the VP16-positive C2C12-RV(D) cells still expressed neuronal differentiation markers, we subjected them to a double-immunostaining assay with the antineuronal $\beta$-tubulin antibody (Tuj1). As shown in Figure 7 , whereas the endogenous neuronal cells expressed only neuronal $\beta$-tubulin and not VP16, as expected, C2C12$\mathrm{RV}(\mathrm{D})$ cells expressed both VP16 (nuclear) and neuronal $\beta$-tubulin (cytoplasmic), indicating that the neuronal cells can survive in the brain and continue to express neuronal markers.

\section{Discussion}

As described above, C2C12 myoblasts have been converted into various cell types, and C2C12 myotubes have been induced to dedifferentiate and redifferentiate into various cell types, but not neurons. Here, we found that direct activation of terminal neuronal differentiation

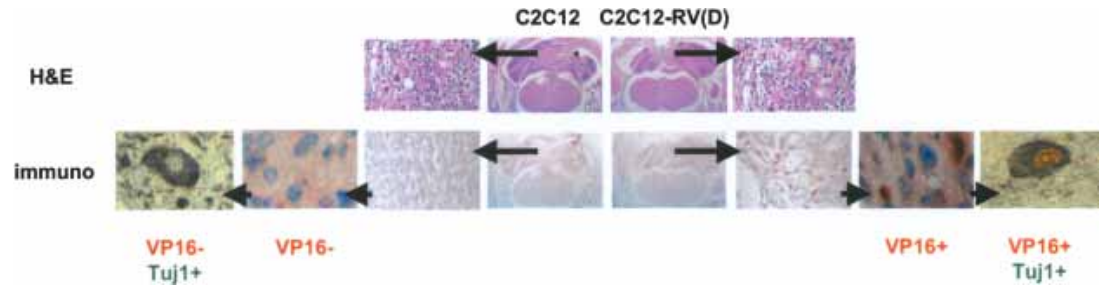
VP16 antibody followed by anti-neuronal $\beta$-tubulin (Tuj1) antibody. The magnified view of C2C12-RV(D) cells shows nuclear localsignal alone.
Figure 7. In vitro differentiated neurons produced by REST-VP16-expressing myoblasts incorporate into adult brain without forming tumors. C2C12 and C2C12-RV(D) cells were inoculated into the cerebellum of adult nude mice. The mice were sacrificed after $8 \mathrm{wk}$ and their brain tissues were formalin-fixed, embedded in paraffin, and used for light microscopic evaluation after staining with $\mathrm{H} \& \mathrm{E}$ or by immunohistochemical analysis with anti- 
genes that are targets of REST/NRSF (mostly structural genes) triggered the activation of other terminal neuronal differentiation genes that are not direct targets of REST/NRSF and produced neurons from C2C12 myoblasts. These findings suggest that such experimental manipulations might be useful in converting other types of progenitor cells to neurons and that the manipulations may circumvent inhibitory regulation in progenitor cells traversing either the nonneuronal differentiation pathways or early stages of neuronal differentiation pathways.

Although REST-VP16 converted myoblasts into neurons, expression of REST-VP16 in fully differentiated muscle fibers failed to convert their fate (data not shown), suggesting that REST-VP16-mediated production of neuronal phenotype is less effective in fully differentiated cell types. Further studies should be performed to determine whether REST-VP16-mediated manipulation of $\mathrm{C} 2 \mathrm{C} 12$ myoblasts, which produced a rapid fate change, also involves a global chromatin modification, as was recently shown to occur during normal NSC development (Xinyu Zhao 2003). REST/NRSF does induce long-term chromatin repression by interacting with the cellular cofactors (Jepsen et al. 2000; Lunyak et al. 2002). Because REST-VP16 binds to the same DNA-binding site as does REST/NRSF but functions as an activator instead of a repressor (Immaneni et al. 2000; Lawinger et al. 2000), we believe that REST-VP16 will block REST/ NRSF-mediated chromatin modification. We are currently examining the chromatin modification induced by REST/NRSF and REST-VP16 in our mammalian chromatin reconstitution system (Rastelli et al. 2001). In addition, myogenic progenitors with enhanced regeneration capabilities were recently isolated (Jankowski et al. 2002), and it will be interesting to determine the role of REST-VP16 expression in those cells. Finally, neurons dying from ischemic insult have been shown to re-express REST/NRSF (Calderone et al. 2003), so experiments should be performed to determine whether expression of REST-VP16 can reverse such neuronal death. The wild-type huntingtin protein was recently found to bind to REST/NRSF and thereby sequester REST/NRSF in the cytoplasm (Zuccato et al. 2003). It was postulated that in the pathology of Huntington disease, the REST/ NRSF-huntingtin protein interaction is lost, causing REST/NRSF to enter the nucleus and repress its target genes. It will be exciting to examine whether RESTVP16 can be used to block this role of REST/NRSF in Huntington disease.

\section{Materials and methods}

\section{Plasmids}

The NheI/Xhol fragment of pcDNA3.1-REST-VP16 (Immaneni et al. 2000) was subcloned into the NheI/Xhol-digested plasmid pBig2r (Strathdee et al. 1999). The clone obtained was confirmed by sequencing the junction region. Construction of $\mathrm{pNaCh}$, pNaCh $\Delta$ RE1, pTLuc, pRE.Tluc, pREST/NRSF, pGal4-VP16, and pREST-VP16 has been described elsewhere (Immaneni et al.
2000; Lawinger et al. 2000). The pCMV- $\beta G A L$ was purchased from Stratagene.

\section{Cell culture}

The mouse myoblast C2C12 cells were purchased from American Type Culture Collection. C2C12 cells were maintained in Minimal Essential Medium (Invitrogen) containing 10\% fetal calf serum (FCS) at $37^{\circ} \mathrm{C}$ in a humidified atmosphere of $5 \% \mathrm{CO}_{2}$ in air. The cells were never grown to confluence. To induce muscle differentiation, the cells were grown to subconfluence in $10 \%$ fetal calf serum-Dulbecco's Modified Eagle's Medium (DMEM), and then the medium was changed to DMEM containing 2\% horse serum (Invitrogen). The medium was changed at least every $2 \mathrm{~d}$. Culture vessels coated with poly-1-lysine (final $20 \mu \mathrm{g} / \mathrm{mL}$ in distilled water; Sigma) were used in the assays. For both calcium imaging and FM1-43 staining, cells were differentiated for $10 \mathrm{~d}$ on glass cover slips coated with $0.005 \%$ poly-L-lysine and $20 \mu \mathrm{g} / \mathrm{mL}$ laminin.

\section{Stable transfection}

$\mathrm{C} 2 \mathrm{C} 12$ cells were plated into $60-\mathrm{mm}$ plates at a density of $5 \times 10^{5}$ per dish the day before the transfection. Two milligrams of pBig2r-REST-VP16 was transfected with $6 \mu \mathrm{L}$ of Fugene 6 (Roche Diagnostics) according to the manufacturer's instructions. Doxycycline ( $2 \mu \mathrm{g} / \mathrm{mL}$; Sigma) was added to the culture and refreshed every $2 \mathrm{~d}$. After $10 \mathrm{~d}$ of hygromycin B $(750 \mu \mathrm{g} / \mathrm{mL}$; Roche) selection, colonies were picked and expanded. Doxycycline-inducible clones were selected by induction of REST-VP16 $2 \mathrm{~d}$ after the removal of doxycycline and identified by Western blot analysis. Two clones (clones 2 and 7) expressed high levels of REST-VP16. After selection, clones were maintained in medium containing $500 \mu \mathrm{g} / \mathrm{mL}$ hygromycin B. During the assays, the concentration of hygromycin B was reduced to $250 \mu \mathrm{g} / \mathrm{mL}$ to avoid removal of the transgene.

\section{SDS-PAGE and Western blotting}

Cells were treated as indicated in the figures, rinsed, and lysed directly in Laemmli sample buffer (Bio-Rad). The lysates were mixed vigorously in a vortex mixer, boiled for $5 \mathrm{~min}$, and subjected to SDS-PAGE. Western blotting was performed as described (Immaneni et al. 2000) using Hybond-P PVDF membranes (Amersham Biosciences) and ECL-plus reagent (Amersham).

\section{Antibodies}

The antibodies used were anti-VP16 (1:1000; Clontech), antisynapsin I (1:1000; MAB355; Chemicon), anti-actin (1:2000, I-19, Santa Cruz Biotech), anti-MAP2 (1:10000 for IF, 1:1000 for Western; HM-2; Sigma), anti-unique $\beta$-tubulin ( $\beta$ III; 1:1000; Tuj1; Covance Research Products), anti- $\alpha$-tubulin (1:10000; B-51-2; Sigma), anti-myosin heavy chain (1:10; MF20; Developmental Studies Hybridoma Bank), anti-secretogranin II antibody (1: 100; QED Bioscience; Roche), anti-synaptophysin I (1:200; Chemicon, catalog no. mab368), anti-synaptotagmin (1:200; Chemicon, catalog no. AB5600), horseradish peroxidase-conjugated anti-mouse, anti-rabbit IgG $(\mathrm{H}+\mathrm{L} ; 1$ :20000; Amersham), HRP-conjugated anti-goat IgG (1:20000; Santa Cruz), fluorescein anti-rabbit IgG (1:250; Vector Lab), and Cy2-labeled antimouse IgG (H+L; 1:1000; Amersham). For Western blotting, anti-neurofilament-160/200kD (1:50; RMdO-20; Zymed), antiGFAP (1:500; DAKO), and anti-myogenin (1:200; Santa Cruz) antibodies were used. 
Reporter gene assays

$\mathrm{C} 2 \mathrm{C} 12$ cells and C2C12-RV clone cells were plated into poly-1lysine-coated 24 -well plates at a density of $8 \times 10^{4}$ cells per well and $1 \times 10^{5}$ cells per well, respectively, the day before transfection. A combination of $100 \mathrm{ng}$ of pTLuc, pRE.Tluc, or pcDNA3.1 and $10 \mathrm{ng}$ of pCMV- $\beta$ GAL was transfected with Lipofectamine 2000 reagent (Invitrogen) according to the manufacturer's instructions. During the transfection, doxycycline was removed from the culture. Six hours after the transfection, the cells were trypsinized, divided into two wells of a six-well plate with or without doxycycline, and cultured for $42 \mathrm{~h}$. The harvested cells were assayed for luciferase and $\beta$-galactosidase as described (Immaneni et al. 2000; Lawinger et al. 2000).

\section{Immunofluorescence analysis of cells}

Cells were fixed for 20-30 min at room temperature with either $4 \%$ paraformaldehyde in phosphate-buffered saline (PBS) or $10 \%$ buffered formalin, rinsed in PBS, permeabilized, and blocked in blocking buffer (5\% nonfat dry milk [Nestle], $0.3 \%$ Triton X-100 [Sigma], and PBS) for $30 \mathrm{~min}$ at room temperature. Primary antibodies were diluted in the blocking buffer and incubated overnight at $4^{\circ} \mathrm{C}$ in humidified conditions. Secondary antibodies were diluted in PBS and incubated for $1 \mathrm{~h}$ at room temperature. For nuclear staining, Hoechst 33328 (Molecular Probes) was used at $0.1 \mu \mathrm{g} / \mathrm{mL}$ in water. Photographs were taken with a Hamamatsu 5880 color CCD camera with a Leica DMR microscope. Double-label images were assembled in Adobe Photoshop. Alternatively, stained cells were covered with slow-fade antifade containing $1 \mu \mathrm{g} / \mathrm{mL}$ DAPI (Molecular Probes) and covered with a coverslip. Staining of cells was observed using a Leica Epifluorescence microscope.

\section{Gene profiling assay}

Total RNA was extracted from C2C12 myoblast cells, C2C12(D) muscle cells, and C2C12-RV(D) neuronal cells using a QIAGEN RNA extraction kit and was subjected to Affymetrix U74Av2 mouse chips. The data were quantified using Affymetrix Microarray Analysis Suite (MAS) 5.0. Estimates of signal intensity and detection p-values were loaded into S-Plus for further analysis. We applied a detection filter to determine which genes should be retained for further analysis; we retained genes that had a detection p-value less than 0.05 on at least one array. Of the 12,488 probe sets on the array, 7496 passed this filter. The remaining 4992 probe sets were dropped. We logtransformed the data and performed a hierarchical cluster analysis to determine which pair of samples was most similar. We used average linkage and a similarity measure based on the Pearson correlation coefficient. By relying on the values from individual probe pairs, we used MAS 5.0 to perform a Wilcoxon signed rank test to compare genes from two chips. Pairwise comparisons were carried out in this manner for each of the three desired comparisons. A summary of the top up-regulated genes in $\mathrm{C} 2 \mathrm{C} 12-\mathrm{RV}(\mathrm{D})$ cells compared to $\mathrm{C} 2 \mathrm{C} 12(\mathrm{D})$ cells and the top up-regulated genes in C2C12(D) cells compared with C2C12-RV(D) cells are shown in Supplementary Tables 1S and $2 \mathrm{~S}$, respectively.

\section{RT-PCR assay}

$\mathrm{C} 2 \mathrm{C} 12$, or $\mathrm{C} 2 \mathrm{C} 12 \mathrm{RV}$ cells were seeded at a density of $5 \times 10^{5}$ cells per $10-\mathrm{cm}$ Petri dish coated with $0.1 \mathrm{mg} / \mathrm{mL}$ polylysine and $0.1 \mu \mathrm{g} / \mathrm{mL}$ of laminin. The cells were grown in DMEM containing $2 \%$ horse serum at $37^{\circ} \mathrm{C}$ and $5 \% \mathrm{CO}_{2}$ tension. At the end of
$10 \mathrm{~d}$, cells were harvested using a cell scraper and washed with $1 \times$ PBS. Total RNA was prepared from these cells using the RNeasy Kit from QIAGEN. RNAs were quantitated spectrophotometrically, and $100 \mathrm{ng}$ of total RNA per sample was used for RT-PCR. Primers used in these reactions had the following sequence: mouse Lrrn1-S585-604, 5'-CCGGAATTCTTTTC CAGTGA-3'; mouse Lrrn1-AS815-796, 5'-AAACACAAAGC TGGGGACAC-3'; mouse SCG10-S1009-1029, 5'-TCCAACC GAAAAATGAGGTC-3'; mouse SCG10-AS1177-1158, 5'-GGC AGGAAGCAGATTACGAG-3'; mouse BDNF-S3612-3631, 5' TTGTTTTGTGCCGTTTACCA-3'; mouse BDNF-AS38423722, 5'-GGTAAGAGAGCCAGCCACTG-3'; mouse SYN1S1127-1146, 5'-TGTCGGGTAACTGGAAGACC-3'; mouse SYN1-AS1360-1341， 5'-AGTTCCACGATGAGCTGCTT-3'; mouse $\beta$-Actin AS-841, $5^{\prime}$-CGCTCGTTGCCAATAGTGATGA CCTG-3'; and mouse $\beta$-actin S-57, 5'-GTCCACACCCG CCACCAGTT-3'. The initial reverse transcription reaction was carried out using the RT-PCR kit as per manufacturer's instructions (QIAGEN). Thereafter, the cDNA was amplified for 25 cycles under the following conditions: Melting at $94^{\circ} \mathrm{C}$ for $1 \mathrm{~min}$, annealing at $55^{\circ} \mathrm{C}$ for $1 \mathrm{~min}$, and extension at $72^{\circ} \mathrm{C}$ for $1 \mathrm{~min}$. The reaction products were analyzed with $2 \%$ agarose gel electrophoresis.

\section{Mitotic inhibition studies}

Cells were cultured for $6 \mathrm{~d}$ in $2 \%$ horse serum-DMEM and then for $14 \mathrm{~d}$ in inhibitor medium ( $2 \%$ horse serum-DMEM and mitotic inhibitors). The final concentrations of inhibitors were 10 $\mu \mathrm{M} 5$-fluoro-2'-deoxyuridine, $10 \mu \mathrm{M}$ uridine, and $1 \mu \mathrm{M}$ cytosine $\beta$ - $d$-arabinofuranoside (Sigma).

\section{Calcium imaging}

Living-cell microscopy to detect depolarization-dependent calcium influx was carried out as described (Bischofberger and Schild 1995). A confocal laser system (Olympus Fluoview FV500) and the fluorescent calcium indicator Fluo-3 (Molecular Probe) were used to measure the intracellular free calcium concentration. Each cell was loaded with Fluo-3 and depolarized with High $\mathrm{KCl}(100 \mathrm{mM})$ Ringer solution as described (Bischofberger and Schild 1995). Fluorescence was measured every 0.25 sec for a total of $5 \mathrm{sec}$. For the glutamate experiment, $10 \mathrm{\mu M}$ glutamate was included in the Ringer solution.

\section{FM1-43 staining}

Cells were loaded with 15 $\mu$ M FM1-43 (Molecular Probes) dissolved in high- $\mathrm{KCl}(100 \mathrm{mM})$ Ringer (external $\left[\mathrm{Na}^{+}\right]$was reduced by an equivalent amount) for $5 \mathrm{~min}$ at room temperature, and washed in Ringer solution without a dye for $15 \mathrm{~min}$ to remove superficial FM1-43. A dye was excited at $470 \mathrm{~nm}$, and the emitted fluorescence was collected at $540 \mathrm{~nm}$.

\section{Cerebellar inoculation of cells into mice}

These experiments were performed following M.D. Anderson Institutional Animal Care and Use guidelines. C2C12 and C2C12-RV(D) (-Dox) cells were centrifuged, and $2 \times 10^{5}$ cells present in $5 \mu \mathrm{L}$ cell growth medium were inoculated in a group of six mice for each experimental condition using an implantable guide-screw system we described elsewhere (Lal et al. 2000). This method, which uses a guide screw, a stylet, a modified Hamilton syringe with a 26-gauge needle, and an infusion 
pump, allows delivery of cells to a very specific location in the brain. Several days before the inoculation, the guide screws were placed in the dorsal cranium of mice. The animals were anesthetized by intraperitoneal injection of $1.2 \%$ avertin solution made in sterile PBS per gram of body weight $100 \%$ avertin solution: $10 \mathrm{~g}$ tribromoethylalcohol $+10 \mathrm{~mL}$ tertiary amyl alcohol) at a dosage of $15-17 \mu \mathrm{L}$ per gram of body weight. The guide screw entry site was marked at a point $2.5 \mathrm{~mm}$ lateral and $1 \mathrm{~mm}$ anterior to the bregma, which is located directly above the caudate nucleus. A small, hand-controlled twist drill was used to make the hole, and a specially devised screwdriver was used to thread the screw into the hole and secure it. After a recovery period of 7-10 d after the guide screws were placed, the cells were inoculated. On the day of implantation, the cells were harvested and resuspended in $\mathrm{Ca}^{++}$- and $\mathrm{Mg}^{++}$-free PBS. The cells were kept on ice until implantation. Mice with the guide screws in place were reanesthetized as described above. The cell suspension was drawn into a Hamilton syringe, which was fitted with a cuff to control the depth of injection. The needle of the Hamilton syringe was slowly lowered into the center of the guide screw until the cuff rested on the screw surface. Up to 10 mice attached to 10 syringes were positioned in a row in a Harvard Apparatus infusion pump that provided continuously controlled slow injection of the cells at a rate of $1 \mu \mathrm{L} / \mathrm{min}$. After the entire volume of the cell suspension was injected, the needles were manually removed, and with a fine forceps, the stylets were positioned in the screw holes to close the system and prevent the injected cells from leaking after inoculation.

Immunhistochemical double-staining of mouse brain paraffin sections

The mice were sacrificed by $\mathrm{CO}_{2}$ inhalation, and further procedures were performed as described (Lawinger et al. 2000; Simmons et al. 2001). Briefly, mouse brains were fixed in neutral buffered formalin, dehydrated, and embedded in paraffin. Fivemicron sections were cut onto charged glass slides and used for light microscopic evaluation after staining by hematoxylin-eo$\sin (\mathrm{H} \& \mathrm{E})$. For immunostaining, sections were deparaffinized and rehydrated in graded ethanols to PBS. Endogenous peroxidase activity was blocked using $3 \%$ hydrogen peroxide for 30 $\mathrm{min}$ at room temperature. Blocking buffer $10 \%$ bovine serum in PBS) was applied for $30 \mathrm{~min}$ at room temperature in a humidified chamber. Anti-VP-16 antibody (Clontech) was used as a 1:50 dilution in blocking buffer overnight at $4^{\circ} \mathrm{C}$. Sections were washed three times in PBS the following day. Conjugated antirabbit antibody (Envision kit, Dako) was applied for $30 \mathrm{~min}$ at room temperature. After washing, the staining was visualized using DAB as a chromogenic substrate (Dako) according to the manufacturer's instructions. The sections were mounted for visualization of staining. The cover slip was them removed and the sections rehydrated. Antigen retrieval was performed in 10 $\mathrm{mM}$ sodium citrate at $\mathrm{pH}$ 6.0, using a microwave-pressure cooker (Kmart) for $10 \mathrm{~min}$ at high power, followed by $12 \mathrm{~min}$ at $20 \%$ power. The slides were cooled for $30 \mathrm{~min}$, washed in PBS, and incubated in blocking buffer for $30 \mathrm{~min}$ at room temperature. An antibody to neuronal class III $\beta$-tubulin (TuJ1, Covance) was diluted 1:10 in blocking buffer and added to the slides. Following an overnight incubation at $4^{\circ} \mathrm{C}$ in a humidified chamber, the slides were washed in PBS. Biotinylated antimouse antibody (Vector Labs) was added for $30 \mathrm{~min}$ at room temperature. The "ABC" reagent was then added and the substrate was developed using a blue chromogen (Vector VIP kit) according to the manufacturer's instructions. Following dehydration in graded ethanols, the slides were mounted and photo- graphed. Specimens were then examined under light microscope and photographed.

\section{Acknowledgments}

We are grateful to Mary Anderlik for her comments on the manuscript and to Gregory N. Fuller and Helen Yang for their help with the immunohistochemical assays. We are also grateful to Gail Mandel for her generous gift of pREST-Express, p73, pBS.REST, and pSDK7, and to Craig Strathdee for pBig2r. This work was supported by grants from the National Cancer Institute (CA 81255). DNA sequencing and veterinary resources were supported by the NIH Cancer Center Support (Core) grant, CA16672.

The publication costs of this article were defrayed in part by payment of page charges. This article must therefore be hereby marked "advertisement" in accordance with 18 USC section 1734 solely to indicate this fact.

\section{References}

Ballas, N., Battaglioli, E., Atouf, F., Andres, M.E., Chenoweth, J., Anderson, M.E., Burger, C., Moniwa, M., Davie, J.R., Bowers, W.J., et al. 2001. Regulation of neuronal traits by a novel transcriptional complex. (Comment). Neuron 31: 353-365.

Betz, W.J. and Bewick, G.S. 1992. Optical analysis of synaptic vesicle recycling at the frog neuromuscular junction. Science 255: 200-203.

Bischofberger, J. and Schild, D. 1995. Different spatial patterns of $[\mathrm{Ca} 2+]$ increase caused by $\mathrm{N}$ - and L-type Ca2+ channel activation in frog olfactory bulb neurones. J. Physiol. 487 (Pt 2): 305-317.

Brivanlou, A.H., Gage, F.H., Jaenisch, R., Jessell, T., Melton, D., and Rossant, J. 2003. Stem cells. Setting standards for human embryonic stem cells. Science 300: 913-916.

Calderone, A., Jover, T., Noh, K.M., Tanaka, H., Yokota, H., Lin, Y., Grooms, S.Y., Regis, R., Bennett, M.V., and Zukin, R.S. 2003. Ischemic insults derepress the gene silencer REST in neurons destined to die. I. Neurosci. 23: 2112-2121.

Cao, B., Zheng, B., Jankowski, R.J., Kimura, S., Ikezawa, M., Deasy, B., Cummins, J., Epperly, M., Qu-Petersen, Z., and Huard, J. 2003. Muscle stem cells differentiate into haematopoietic lineages but retain myogenic potential. Nat. Cell Biol. 5: 640-646.

Chawla, S., Skepper, J.N., Hockaday, A.R., and Huang, C.L. 2001. Calcium waves induced by hypertonic solutions in intact frog skeletal muscle fibres. J. Physiol. 536: 351-359.

Chong, J.A., Tapia-Ramirez, J., Kim, S., Toledo-Aral, J.J., Zheng, Y., Boutros, M.C., Altshuller, Y.M., Frohman, M.A., Kraner, S.D., and Mandel, G. 1995. REST: A mammalian silencer protein that restricts sodium channel gene expression to neurons. Cell 80: 949-957.

Dandoy-Dron, F., Griffond, B., Mishal, Z., Tovey, M.G., and Dron, M. 2003. Scrg1, a novel protein of the CNS is targeted to the large dense-core vesicles in neuronal cells. Eur. J. Neurosci. 18: 2449-2459.

Deasy, B.M., Jankowski, R.J., and Huard, J. 2001. Muscle-derived stem cells: Characterization and potential for cell-mediated therapy. Blood Cells Mol. Dis. 27: 924-933.

Frisen, J. 2002. Stem cell plasticity? Neuron 35: 415-418.

Galli, R., Borello, U., Gritti, A., Minasi, M.G., Bjornson, C., Coletta, M., Mora, M., De Angelis, M.G., Fiocco, R., Cossu, G., et al. 2000. Skeletal myogenic potential of human and mouse neural stem cells. Nat. Neurosci. 3: 986-991.

Galli, R., Gritti, A., Bonfanti, L., and Vescovi, A.L. 2003. Neural 
stem cells: An overview. Circ. Res. 92: 598-608.

Goldman, J.E. 2003. What are the characteristics of cycling cells in the adult central nervous system? J. Cell Biochem. 88: 2023

Horner, P.J. and Gage, F.H. 2002. Regeneration in the adult and aging brain. Arch. Neurol. 59: 1717-1720.

Immaneni, A., Lawinger, P., Zhao, Z., Lu, W., Rastelli, L., Morris, J.H., and Majumder, S. 2000. REST-VP16 activates multiple neuronal differentiation genes in human NT2 cells. Nucleic Acids Res. 28: 3403-3410.

Jankowski, R.J., Deasy, B.M., and Huard, J. 2002. Muscle-derived stem cells. Gene Ther. 9: 642-647.

Jepsen, K., Hermanson, O., Onami, T.M., Gleiberman, A.S., Lunyak, V., McEvilly, R.J., Kurokawa, R., Kumar, V., Liu, F., Seto, E., et al. 2000. Combinatorial roles of the nuclear receptor corepressor in transcription and development. Cell 102: $753-763$.

Katagiri, T., Yamaguchi, A., Komaki, M., Abe, E., Takahashi, N., Ikeda, T., Rosen, V., Wozney, J.M., Fujisawa-Sehara, A., and Suda, T. 1994. Bone morphogenetic protein-2 converts the differentiation pathway of $\mathrm{C} 2 \mathrm{C} 12$ myoblasts into the osteoblast lineage. (Erratum appears in I. Cell. Biol. 1995. 128: following 713). J. Cell Biol. 127: 1755-1766.

Keyoung, H.M., Roy, N.S., Benraiss, A., Louissaint Jr., A., Suzuki, A., Hashimoto, M., Rashbaum, W.K., Okano, H., and Goldman, S.A. 2001. High-yield selection and extraction of two promoter-defined phenotypes of neural stem cells from the fetal human brain. Nat. Biotechnol. 19: 843-850.

Lal, S., Lacroix, M., Tofilon, P., Fuller, G.N., Sawaya, R., and Lang, F.F. 2000. An implantable guide-screw system for brain tumor studies in small animals. J. Neurosurg. 92: 326333.

Lawinger, P., Venugopal, R., Guo, Z.S., Immaneni, A., Sengupta, D., Lu, W., Rastelli, L., Marin Dias Carneiro, A., Levin, V., Fuller, G.N., et al. 2000. The neuronal repressor REST/NRSF is an essential regulator in medulloblastoma cells. (erratum appears in Nat Med 2000 Sep;6(9):1062). Nat. Med. 6: 826831.

Lunyak, V.V., Burgess, R., Prefontaine, G.G., Nelson, C., Sze, S.H., Chenoweth, J., Schwartz, P., Pevzner, P.A., Glass, C., Mandel, G., et al. 2002. Corepressor-dependent silencing of chromosomal regions encoding neuronal genes. Science 298: $1747-1752$.

Matteoli, M., Verderio, C., Krawzeski, K., Mundigl, O., Coco, S., Fumagalli, G., and De Camilli, P. 1995. Mechanisms of synaptogenesis in hippocampal neurons in primary culture. $J$. Physiol. Paris 89: 51-55.

McGann, C.J., Odelberg, S.J., and Keating, M.T. 2001. Mammalian myotube dedifferentiation induced by newt regeneration extract. Proc. Natl. Acad. Sci. 98: 13699-13704.

Murthy, V.N. and Stevens, C.F. 1998. Synaptic vesicles retain their identity through the endocytic cycle. Nature 392: 497501.

Nunes, M.C., Roy, N.S., Keyoung, H.M., Goodman, R.R., McKhann II, G., Jiang, L., Kang, J., Nedergaard, M., and Goldman, S.A. 2003. Identification and isolation of multipotential neural progenitor cells from the subcortical white matter of the adult human brain. Nat. Med. 9: 439-447.

Odelberg, S.J., Kollhoff, A., and Keating, M.T. 2000. Dedifferentiation of mammalian myotubes induced by msx1. Cell 103: 1099-1109.

Ogoshi, F. and Weiss, J.H. 2003. Heterogeneity of Ca2+-permeable AMPA/kainate channel expression in hippocampal pyramidal neurons: Fluorescence imaging and immunocytochemical assessment. J. Neurosci. 23: 10521-10530.

Ourednik, J., Ourednik, V., Lynch, W.P., Schachner, M., and
Snyder, E.Y. 2002. Neural stem cells display an inherent mechanism for rescuing dysfunctional neurons. Nat. Biotechnol. 20: 1103-1110.

Panchision, D.M. and McKay, R.D. 2002. The control of neural stem cells by morphogenic signals. Curr. Opin. Genet. Dev. 12: $478-487$.

Paquette, A.J., Perez, S.E., and Anderson, D.J. 2000. Constitutive expression of the neuron-restrictive silencer factor (NRSF)/REST in differentiating neurons disrupts neuronal gene expression and causes axon pathfinding errors in vivo. Proc. Nat1. Acad. Sci. 97: 12318-12323.

Park, K.I., Lachyankar, M., Nissim, S., and Snyder, E.Y. 2002a. Neural stem cells for CNS repair: State of the art and future directions. Adv. Exp. Med. Biol. 506: 1291-1296.

Park, K.I., Teng, Y.D., and Snyder, E.Y. 2002b. The injured brain interacts reciprocally with neural stem cells supported by scaffolds to reconstitute lost tissue. Nat. Biotechnol. 20: $1111-1117$.

Peng, H. and Huard, J. 2003. Stem cells in the treatment of muscle and connective tissue diseases. Curr. Opin. Pharmacol. 3: 329-333.

Pincus, D.W., Keyoung, H.M., Harrison-Restelli, C., Goodman, R.R., Fraser, R.A., Edgar, M., Sakakibara, S., Okano, H., Nedergaard, M., and Goldman, S.A. 1998. Fibroblast growth factor-2/brain-derived neurotrophic factor-associated maturation of new neurons generated from adult human subependymal cells. Ann. Neurol. 43: 576-585.

Rastelli, L., Robinson, K., Xu, Y., and Majumder, S. 2001. Reconstitution of enhancer function in paternal pronuclei of one-cell mouse embryos. Mol. Cell. Bioil. 21: 5531-5540.

Ross, S.E., Greenberg, M.E., and Stiles, C.D. 2003. Basic helixloop-helix factors in cortical development. Neuron 39: 1325.

Roy, N.S., Wang, S., Jiang, L., Kang, J., Benraiss, A., HarrisonRestelli, C., Fraser, R.A., Couldwell, W.T., Kawaguchi, A., Okano, H., et al. 2000. In vitro neurogenesis by progenitor cells isolated from the adult human hippocampus. (Comment). Nat. Med. 6: 271-277.

Sanchez-Ramos, J.R. 2002. Neural cells derived from adult bone marrow and umbilical cord blood. J. Neurosci. Res. 69: 880893.

Schoenherr, C.J. and Anderson, D.J. 1995. The neuron-restrictive silencer factor (NRSF): A coordinate repressor of multiple neuron-specific genes. Science 267: 1360-1363.

Schoenherr, C.J., Paquette, A.P., and Anderson, D.J. 1996. Identification of potential target genes for the neuron-restrictive silencer factor. Proc. Natl. Acad. Sci. 93: 9881-9886.

Shen, X., Collier, J.M., Hlaing, M., Zhang, L., Delshad, E.H., Bristow, J., and Bernstein, H.S. 2003. Genome-wide examination of myoblast cell cycle withdrawal during differentiation. Dev. Dyn. 226: 128-138.

Snyder, E.Y. and Vescovi, A.L. 2000. The possibilities/perplexities of stem cells. Nat. Biotechnol. 18: 827-828.

Simmons, M.L., Lamborn, K.R., Takahashi, M., Chen, P., Israel, M.A., Berger, M.S., Godfrey, T., Nigro, J., Prados, M., Chang, S., et al. 2001. Analysis of complex relationships between age, p53, epidermal growth factor receptor, and survival in glioblastoma patients. Cancer Res. 61: 1122-1128.

Strathdee, C.A., McLeod, M.R., and Hall, J.R. 1999. Efficient control of tetracycline-responsive gene expression from an autoregulated bi-directional expression vector. Gene 229: 21-29.

Teboul, L., Gaillard, D., Staccini, L., Inadera, H., Amri, E.Z., and Grimaldi, P.A. 1995. Thiazolidinediones and fatty acids convert myogenic cells into adipose-like cells. J. Biol. Chem. 270: $28183-28187$. 
Watanabe et al.

Tooze, S.A., Martens, J.M.M., and Huttner, W.B. 2001. Secretory granule biogenesis: Rafting to the SNARE. Trends Cell Biol. 11: 116-122.

Tsai, R.Y., Kittappa, R., and McKay, R.D. 2002. Plasticity, niches, and the use of stem cells. Dev. Cell 2: 707-712.

Walsh, K. and Perlman, H. 1997. Cell cycle exit upon myogenic differentiation. Curr. Opin. Genet. Dev. 7: 597-602.

Wurmser, A.E. and Gage, F.H. 2002. Stem cells: Cell fusion causes confusion. Nature 416: 485-487.

Xinyu Zhao, T.U., Christie, B.R., Barkho, B., McConnell, M.J., Nakashima, K., Lein, E.S., Eadie, B.D., Willhoite, A.R., Muotri, A.R., Summers, R.G., et al. 2003. Mice lacking methyl-CpG binding protein 1 have deficits in adult neurogenesis and hippocampal function. Proc. Natl. Acad. Sci. 100: 6777-6782.

Zuccato, C., Tartari, M., Crotti, A., Goffredo, D., Valenza, M., Conti, L., Cataudella, T., Leavitt, B.R., Hayden, M.R., Timmusk, T., et al. 2003. Huntingtin interacts with REST/NRSF to modulate the transcription of NRSE-controlled neuronal genes. Nat. Genet. 35: 76-83. 


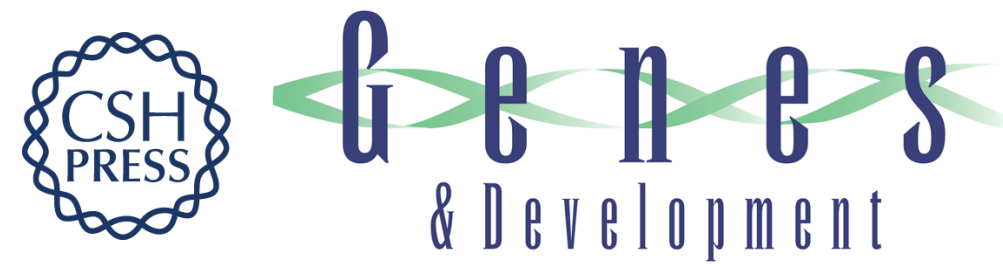

\section{Conversion of myoblasts to physiologically active neuronal phenotype}

Yumi Watanabe, Sei Kameoka, Vidya Gopalakrishnan, et al.

Genes Dev. 2004, 18:

Access the most recent version at doi:10.1101/gad.1179004

\section{Supplemental http://genesdev.cshlp.org/content/suppl/2004/04/20/1179004.DC1 \\ Material}

References This article cites 52 articles, 14 of which can be accessed free at: http://genesdev.cshlp.org/content/18/8/889.full.html\#ref-list-1

\section{License}

Email Alerting Service right corner of the article or click here.

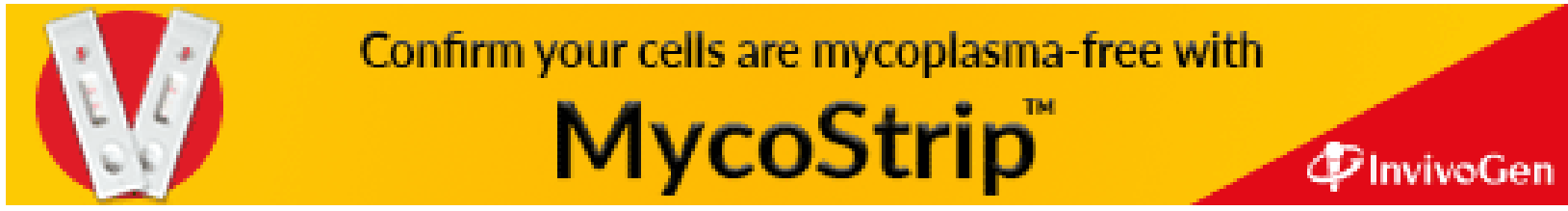

